\title{
An Unusual Case of Primary Retroperitoneal Germ Cell Tumour in a Young Man
}

\author{
Maria João Serpa ${ }^{1}$, Susana Franco ${ }^{1}$, Diana Repolho ${ }^{1}$, Francisco Branco ${ }^{2}$, João Gramaça ${ }^{2}$, José Ferreira Júnior ${ }^{1}$ \\ ${ }^{1}$ Internal Medicine Department, Hospital Beatriz Ângelo, Lisbon, Portugal \\ ${ }^{2}$ Oncology Department, Hospital Beatriz Ângelo, Lisbon, Portugal
}

Received: $14 / 04 / 2018$

Accepted: 08/05/2018

Published: 29/05/2018

How to cite this article: Serpa MJ, Franco S, Repolho D, Branco F, Gramaça J, Ferreira Júnior J. An unusual case of primary retroperitoneal germ cell tumour in a young man. EJCRIM 2018;5: doi:10.12890/2018_000900.

Conflicts of Interests: The Authors declare that there are no competing interests.

This article is licensed under a Commons Attribution Non-Commercial 4.0 License

\section{ABSTRACT}

Some $2-5 \%$ of germ cell tumours are of extragonadal origin, with a retroperitoneal location being very rare. The majority of retroperitoneal germ cell tumours have metastasized from a testicular tumour. These tumours are diagnosed incidentally or symptomatically and nearly all present with high alpha-fetoprotein and lactate dehydrogenase levels.

We describe the unusual case of a 31-year-old man with a yolk-sac, retroperitoneal germ cell tumour, with normal serum alpha-fetoprotein and lactate dehydrogenase levels, which has not previously been described. A testicular tumour was excluded by physical examination and additional tests. Our diagnosis was based on a high level of suspicion and histopathological results. As far as we know, this is the first case described with these characteristics.

\section{LEARNING POINTS}

- Extragonadal germ cell tumours are rare but can have fatal consequences if undiagnosed.

- The usual laboratory markers of the disease were absent in our patient.

- A high level of suspicion is required for diagnosis and close follow-up is required.

\section{KEYWORDS}

Neoplasms, germ cell and embryonal, male germ cell tumor, extragonadal, non-seminomatous, yolk-sac tumour, alpha-fetoproteins

\section{CASE DESCRIPTION}

We describe the case of a 31-year old man who was otherwise healthy apart from right low back pain for the previous 4 months, at the L1-L3 level, which had worsened in the last 2 weeks, was severe (8/10) and radiated to the right groin. There was no history of trauma. The patient described the pain as aching for most of the time with occasional stabbing pain, which was neither alleviated nor aggravated by rest, exercise, heat, cold or NSAIDs. He denied fever, sweating, urinary, respiratory or intestinal symptoms, numbness or sphincter incontinence. On observation, the patient was pale, but his vital signs were within the normal range. Laségue's sign was absent bilaterally and the patient's walk was unaffected. His testicles had normal dimensions and were symmetrical, but the right testicle was tender on palpation, without any inflammatory signs.

Laboratory results were normal except for the presence of mild normochromic normocytic anaemia (haemoglobin $12.6 \mathrm{~g} / \mathrm{dl}$ ) due to low folic acid. His peripheral blood smear, iron kinetics and B12 vitamin levels were normal. His proteinogram was unremarkable. He tested negative for HIV and hepatitis. His lactate dehydrogenase, human chorionic gonadotropin and alpha-fetoprotein levels were normal. 
His testicular ultrasound revealed normal testicles which were relatively symmetrical and had a regular outline. The testicles had a homogeneous echotexture, without focal lesions bilaterally, and with normal Doppler US, excluding the need for a testicular biopsy.

A thoracic, abdominal and pelvic CT scan revealed a right paravertebral space-occupying mass measuring $58 \times 33 \mathrm{~mm}$ which displaced the right anterior crus of the diaphragm, and was well defined and homogeneous, and also showed axillary adenomegaly bilaterally of less than $1 \mathrm{~cm}$. A CT-guided biopsy of the mass was performed. Histological examination showed a primary yolk-sac tumour of the retroperitoneal region cTON3MOSO, stage IIC, a good International Germ Cell Consensus Classification (IGCCCG) prognosis and a good ECOG performance status of 0 . Immunohistochemical stains for placental alpha-fetoprotein and cytokeratin AE1/AE3, CAM 5.2, CD56 and CD117 were positive in the tumour cells.

The patient's pain was controlled with pregabalin, tapentadol and paracetamol.

Sperm was collected from the patient for storage before the initiation of three cycles of BEP (bleomycin, etoposide and cisplatin).

The patient's follow-up will consist of cancer staging at 3-month intervals for the first year, high-dose chemotherapy, resection surgery of the residual mass, retroperitoneal lymph node dissection and preventive orchiectomy.

\section{DISCUSSION}

The unusual specific location of the pain as well as its characteristics, which did not seem to be due to lumbago, alerted us to seek another diagnosis.

Primary GCT of extragonadal origin without a primary gonadal lesion are rare ${ }^{[1,3]}$. In our patient, there was no clinical, analytical or imaging evidence of a testicular tumour, but close follow-up will be needed to check for testicular cancer. Nevertheless we collected sperm before chemotherapy as preservation of fertility is particularly important in young patients ${ }^{[8]}$.

There are no treatment guidelines for extragonadal variants of GCT so therapy is mainly extrapolated from that for gonadal GCT ${ }^{[6]}$. As retroperitoneal GCT have comparable clinical behaviour to gonadal GCT ${ }^{[1]}$, treatment is nearly the same, with the exception of orchidectomy ${ }^{[4]}$, which might however be performed to exclude a source of recurrence and metastases from occult disease ${ }^{[4]}$.

The majority of extragonadal tumours can be cured with chemotherapy. For retroperitoneal non-seminomatous GCT, the treatment is cisplatin-based chemotherapy (as would be used for a testicular non-seminomatous GCT) ${ }^{[10]}$.

However, patients with extragonadal GCT have a worse prognosis than those with testicular GCT within the same prognostic IGCCCG group, or than those with seminomas ${ }^{[9]}$. Patients with retroperitoneal non-seminomatous GCT have a $10 \%$ chance of developing testicular cancer within 10 years, which highlights the importance of close follow-up for a long period ${ }^{[9]}$.

On the other hand, patients with primary retroperitoneal GCT have longer survival than those with relapsed metastatic testicular GCT ${ }^{[1,9]}$, only $30 \%$ of whom can be cured with high-dose chemotherapy ${ }^{[1]}$.

Yolk-sac tumours, the histological type in our clinical case, are grey tumours with areas of necrosis and haemorrhage ${ }^{[6]}$. Microscopically, different patterns that recapitulate the yolk sac are seen but one should predominate ${ }^{[6]}$. Yolk-sac tumours are characterized by high serum alpha-fetoprotein levels ${ }^{[7]}$, which however were not seen in our patient. This tumour marker is an important follow-up guide for treatment response, recurrence or metastasis. We do not know if normal alpha-fetoprotein levels can affect treatment responsive or prognosis. We will follow a strict and close follow-up protocol with clinical examination and complementary examinations to help us answer those questions. To our knowledge this is the first case described with a primary retroperitoneal yolk-sac tumour with a normal serum alpha-fetoprotein level.

\section{REFERENCES}

1. Busch J, Seidel C, Zengerling F. Male extragonadal germ cell tumors of the adult. Oncol Res Treat 2016;39:140-144.

2. Bayrack O, Karatas O, Bayrak R, Çimentepe E, Unal D, Deniz N. Primary extragonadal retroperitoneal pure yolk sac tumor. Eur J Gen Med 2008;5:239-241.

3. Murat E, Dagdemir A, Bilgici M, Sullu Y. Primary yolk sac tumor of the retroperitoneal region. Contemp Oncol 2013;17:530-532.

4. Punjani N, Winquist E, Power N. Do retroperitoneal extragonadal germ cell tumors exist? Can Urol Assoc J 2015;9:381-384.

5. Choudaha P, Likhar KS, Gupta SG, Patle Y, Hazari RA. Extragonadal retroperitoneal pure yolk sac tumour. People's J Scientific Res 2014;7:47.

6. Nair W, Kiran HS, Shanthala PR. Pure primary extragonadal retroperitoneal yolk sac tumor in a young child: a case report. J Clin Diagn Res $2017 ; 11$ :ED09-ED11.

7. Wada S, Yoshimura R, Nishisaka N, Kishimoto T, Ikehara T, Masuda C, et al. Primary retroperitoneal pure yolk-sac tumor in an adult male. Scand J Urol Nephrol 2001;35:515-517.

8. Gao Y, Jiang J, Liu Q. Extragonadal malignant germ cell tumors: a clinicopathological and immunohistochemical analysis of 48 cases at a single Chinese institution. Int J Clin Exp Pathol 2015;8:5650-5657.

9. Bokemeyer C, Nichols C, Droz JP, Schmoll HJ, Horwich A, Gerl A, et al. Extragonadal germ cell tumors of the mediastinum and retroperitoneum: results from an international analysis. J Clin Oncol 2002;20:1864-1873.

10. Kantoff P. Extragonadal germ cell tumors involving the mediastinum and retroperitoneum. Waltham, MA: UpToDate; 2017. Available from https:/www.uptodate.com/ contents/extragonadal-germ-cell-tumors-involving-the-mediastinum-and-retroperitoneum (accessed 15 May 2018). 